Article

\title{
Physical and Theoretical Modeling of the Nitrogen Content of Duplex Stainless Steel Weld Metal: Shielding Gas Composition and Heat Input Effects
}

\author{
Balázs Varbai $[$ and Kornél Májlinger * \\ Department of Materials Science and Engineering, Budapest University of Technology and Economics, \\ H-1111 Budapest, Hungary \\ * Correspondence: welding@att.bme.hu
}

Received: 13 June 2019; Accepted: 4 July 2019; Published: 7 July 2019

\begin{abstract}
Duplex stainless steels (DSSs) are gaining more and more attention in corrosion-resistant applications and also in the transport and automotive industry. The outstanding mechanical and corrosion properties of DSSs highly depends on the austenite-to-ferrite phase balance (A/F). This phase ratio can shift in a large scale during welding. Thus, the heat input and the shielding gas composition should be optimized. Nitrogen addition to argon shielding is frequently used in DSS welding, because it is a potent austenite former. The dissolved nitrogen content in the heat-affected zone and the weld metal (WM) predetermines the A/F. To determine the effect of heat input and nitrogen content in shielding gas, two different heat inputs and six different gas compositions were used in autogenous tungsten inert gas welding. An improved theoretical model was established in order to simulate the WM dissolved nitrogen content, which calculates it with less error than the initial models. The correlation between nitrogen content and arc voltage was also determined. This improved model delivers the basics for shielding gas selection and the subsequent weld design for optimal A/F for industrial applications.
\end{abstract}

Keywords: duplex stainless steel (DSS); welding; shielding gas nitrogen content; weld metal nitrogen content

\section{Introduction}

Among the growing application of high strength steels [1-4], duplex stainless steels (DSSs) are gaining increasing attention from the chemical, petrol, and transportation [5-7] industries, thanks to their mechanical properties and corrosion resistance [8-11]. However, the industrial application of DSSs is in only $\sim 1 \%$ among all the types of stainless steels [12]. One of the reasons for this is the weldability $[9,13]$, which reduces the numbers of industrial applications. All of the DSSs solidify as delta ferrite $(\delta)$ [14]. The duplex austenitic $(\gamma)$-ferritic $(\delta)$ microstructure evolves during solid-state phase transformation [15-18]. The driving force of this transformation is the atomic nitrogen diffusion in the $\delta$ matrix. DSSs are nitrogen alloyed, not only because of metallurgical reasons (as nitrogen is a strong $\gamma$ former) but also to increase mechanical properties, such as yield strength and also corrosion resistance $[19,20]$. Thus, the base materials' (BMs) nitrogen content plays a significant role during DSS welding. During arc welding of DSSs, the nitrogen loss from the weld metal (WM) leads toward more ferritic microstructures and to the loss of the abovementioned properties [21,22]. In order to balance this nitrogen loss, nitrogen $\left(N_{2}\right)$-argon (Ar) (or helium) mixed shielding gases are used in industrial applications for DSS tungsten inert gas (TIG) welding [23-25]. The $N_{2}$ dissociates at the arc plasma temperature and the atomic nitrogen can dissolve in the molten pool [26]. During the solidification, this dissolved nitrogen $(\underline{N})$ can enhance its $\gamma$ forming effect on the $\delta \rightarrow \delta+\gamma$ phase transformation. However, for this diffusion-driven phase transformation, adequate diffusion time is needed, which is expressed 
in the cooling time between $1200{ }^{\circ} \mathrm{C}$ and $800{ }^{\circ} \mathrm{C}\left(\Delta \mathrm{t}_{12 / 8}\right)$ in the case of DSSs [27,28]. On one hand, if the cooling time is insufficiently short, the $\underline{N}$ can be entrapped in $\delta$, forming different kinds of chromium nitrides $\left(\mathrm{CrN}\right.$ or $\left.\mathrm{Cr}_{2} \mathrm{~N}\right)[16,29,30]$. The reason for this is the significant solubility decrease of nitrogen in $\delta$ $(\sim 0.01 \mathrm{wt} \%)$ below $\sim 700{ }^{\circ} \mathrm{C}$ [31]. On the other hand, if sufficient $\Delta \mathrm{t}_{12 / 8}$ time is provided after welding, the $\gamma$ content is increasing with the amount of $\underline{N}$ (and the shielding gases' $N_{2}$ content) [32-34].

For the quantification of $\underline{N}$ dissolution during welding, different models exist. Du Toit developed a model for the quantification of nitrogen transfer during autogenous arc welding of austenitic stainless steels [35]. This kinetic model takes both nitrogen absorption and desorption into attention during welding; thus, her model can be used for $\underline{N}$ content prediction in the molten pool during welding in the case of austenitic stainless steels. In the case of DSSs, an improved model is needed for the solubility prediction, as DSSs have higher nitrogen content as an alloying element $(>0.15 \mathrm{wt} \%)$, which is needed to be taken into account. Rokanopoulou et al. [36] recently modified this model for the case of DSS plasma arc welding (PAW). Their model is adequate for DSS molten pool $\underline{N}$ content prediction for lower nitrogen containing shielding gases, but sometimes, exaggerated results are given (such as $\underline{N}=0.78 \%$ ), which is over the equilibrium solubility limit of nitrogen in molten DSS grades. The possible reason for this is the complex interaction processes between the plasma-generating and shielding gases and the molten pool during PAW. Hosseini measured a linear regression for the prediction of nitrogen desorption from the WM as a function of arc energy [37].

The aim of our research was to further develop and specify these existing models for the case of autogenous DSS TIG welding of DSS 2205 with different $\mathrm{Ar}+\mathrm{N}_{2}$ gas mixtures.

\section{Materials and Methods}

For our investigation, physical and theoretical models were done, using different $\mathrm{Ar}+\mathrm{N}_{2}$ shielding gas mixtures in the case of autogenous TIG welding for DSS. After the physical modeling, our improved theoretical model was compared to the measured values for model validation.

\subsection{The DSS Base Material}

The base material for the physical welding simulations was the industrially most frequently used X2CrNiMoN22-5-3 (DSS 2205) duplex stainless steel. The nominal chemical composition of the base material can be seen in Table 1 . The initial nitrogen content $(\% N)$ was measured by HORIBA EMGA-620W nitrogen analyzer (Kyoto, Japan). The dimension of the welded sheets was $150 \times 80 \times 5 \mathrm{~mm}^{3}$.

Table 1. The nominal chemical composition of the base material duplex stainless steel (DSS) 2205.

\begin{tabular}{|c|c|c|c|c|c|c|c|c|c|c|c|}
\hline \multirow{2}{*}{$\begin{array}{l}\text { DSS } \\
\text { Grade }\end{array}$} & \multirow{2}{*}{ Thickness } & \multicolumn{10}{|c|}{ Chemical Composition (wt \%) } \\
\hline & & $\% C$ & $\% C r$ & $\% \mathrm{Ni}$ & $\% M n$ & $\% M o$ & $\% N^{1}$ & $\% C u$ & $\% S i$ & $\% P$ & $\% S$ \\
\hline 2205 & $5 \mathrm{~mm}$ & 0.02 & 21.6 & 4.7 & 1.9 & 3.1 & $0.181 \pm 0.003$ & 0.3 & 0.76 & 0.03 & 0.001 \\
\hline
\end{tabular}

\subsection{Details of the Physical Weld Simulation}

\subsubsection{Welding Parameters}

In order to investigate the nitrogen solubility in the WM, autogenous TIG welding was performed on the DSS 2205 sheets with $0-50$ vol. \% $N_{2}$ content in the pure (99.996 vol. \%) Ar shielding gas. For the TIG welding, ESAB CaddyTIG 200 power source was used, with Ø $2.4 \mathrm{~mm}$ WC20 electrode on DC(direct current, electrode on negative) polarity. In our research, arc energy (in $\mathrm{kJ} \cdot \mathrm{mm}^{-1}$ ) is being used instead of heat input. The reason for this is the fact that the nitrogen addition to the shielding gas can significantly modify the thermal conductivity of the arc plasma, and thus, the thermal efficiency value of 1.0 is being used and presumed in every case. Two arc energy values were applied: 0.53 and $0.68 \mathrm{~kJ} \cdot \mathrm{mm}^{-1}$. It was very important to keep these arc energy values constant with the different $N_{2}$ contents in the 
shielding gases. The welding speed was a constant $3 \mathrm{~mm} \cdot \mathrm{s}^{-1}$ in all cases. The shielding gas flow rate was $11 \mathrm{~L} \cdot \mathrm{min}^{-1}$ in every case. The arc length was a constant $2 \mathrm{~mm}$, and the electrode tip angle was $30^{\circ}$.

\subsubsection{Evaluation Methods}

For the geometrical measurements of the weld beads, an Olympus SZX16 stereo-microscope (Tokyo, Japan) was used. The geometrical measurements were done on at least 3 samples. The metallographic images were taken using the Olympus PMG3 optical microscope (Tokyo, Japan). The $\gamma$ content measurements were done using Image-Pro ${ }^{\circledR} 9$ image analyzer software (Media Cybernetics Inc., Rockville, MD, USA). The application of image analysis has recently been popular with researchers for DSS characterization [38,39]. A brief description of our self-developed method [40] follows. The cut weld cross-sections were prepared for standard metallography: mounted, ground to 4000 grit paper, and polished to $3 \mu \mathrm{m}$ diamond suspension. Next, the samples were color etched, using Berahas II etchant ( $85 \mathrm{~mL} \mathrm{H}_{2} \mathrm{O}+15 \mathrm{~mL} \mathrm{HCl}+1 \mathrm{~g} \mathrm{~K}_{2} \mathrm{~S}_{2} \mathrm{O}_{5}$ ). A $2 \times 12 \mathrm{~s}$ etching cycle (total of $24 \mathrm{~s}$ etching time) was used, which was found to be optimal in our previous work [40]. The samples were rinsed in ethanol in between the two, $12 \mathrm{~s}$, etching cycles. With the optimal etching, the highest contrast can be achieved between the $\delta$ (dark areas) and $\gamma$ phases (light areas). With a histogram-based thresholding process, the dark and light areas can easily be separated to black and white colors. In the thresholded images, the amount of white areas, which is equal to the $\gamma$ content, can be quantified using the image analyzing software. At least 10 images were evaluated for $\gamma$ content measurements in every case.

The total dissolved nitrogen content in the WM $\left(N_{\text {steel }}\right)$ was measured via the combustion method, using HORIBA EMGA-620W oxygen/nitrogen analyzer (Kyoto, Japan). At least 4 samples, weighing $\sim \mathrm{g}$, were machined out from the middle of the WM in every case from the steady-state welded sections. The steady-state of the $\sim 120 \mathrm{~mm}$ long weld seams was achieved after $\sim 60 \mathrm{~mm}$. The accuracy of the measurement is $0.001 \mathrm{wt} \%$, which is sufficient in our case.

\section{Improved Theoretical Model for Nitrogen Solubility Calculation in the Molten Pool}

Our improved model of N kinetics during autogenous TIG welding of DSS is based on Du Toit's model [35] for austenitic stainless-steel welding and Rokanopoulou's model [36] for plasma arc welding of DSS.

The representation of the basic assumption of the theoretical model can be seen in Figure 1. The atomic nitrogen enters the weld pool from two sources: from the arc plasma $(N(g)$, Figure 1a) and from the BM (\%N, Figure 1c). The desorption of nitrogen from the molten pool takes place also through two different mechanisms: desorption of $\underline{N}$ to the arc atmosphere (Figure 1b) and desorption of $\underline{N}$ to the BM (Figure 1d). Under steady-state conditions, the absorption (Figure 1a,c) and desorption (Figure 1b,d) mechanisms are in equilibrium. A few assumptions are made as a boundary condition for the theoretical model: (1) The arc plasma is completely covering the molten pool; (2) the nitrogen concentration in the molten pool, and in the solidified WM, is uniform; and (3) the model does not take into consideration nitrogen porosity formation during welding.

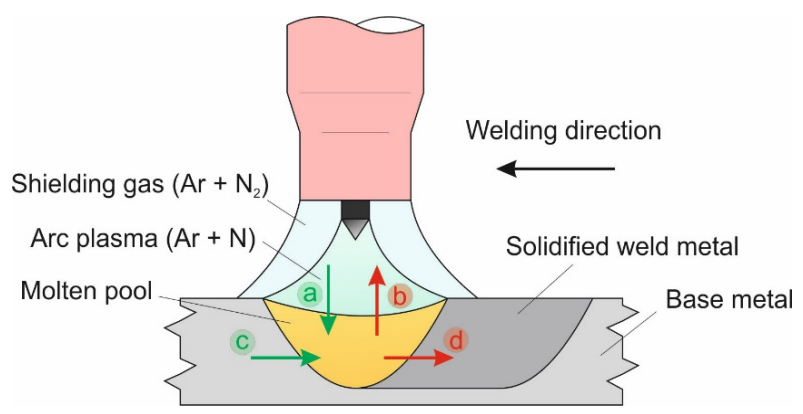

Figure 1. Schematic illustration of the nitrogen absorption: $(\mathbf{a}, \mathbf{c})$, and desorption: $(\mathbf{b}, \mathbf{d})$ during autogenous tungsten inert gas (TIG) welding of DSS. 


\subsection{Nitrogen Absorption from the Arc Plasma}

The nitrogen absorption from the arc plasma is represented in Figure 1a. At the arc plasma temperature, the molecular nitrogen in the shielding gas $N_{2}$ dissociates from nitrogen atoms $N(g)[26,41]$. The $N(g)$ dissolves in the molten pool $(\underline{N}$ in $(w t \%))$ :

$$
N(g) \rightarrow \underline{N}(\text { wt } \%) .
$$

The $\underline{N}$ change over time can be expressed according to Du Toit [35]:

$$
\frac{d \underline{N}(\mathrm{wt} \%)}{d t}=\frac{100 A K_{a}}{\rho V}\left[N(g)-\frac{N_{\text {steel }}}{K}\right]
$$

where $A$ is the molten pool surface in $\mathrm{m}^{2}, K_{a}$ is the reaction rate constant for Equation (1) in $\mathrm{kg} \cdot \mathrm{m}^{-2} \cdot \mathrm{s}^{-1} \cdot \mathrm{atm}^{-1}, \rho$ is the density of the molten pool at the welding temperature in $\mathrm{kg} \cdot \mathrm{m}^{-3}, V$ is the molten pool volume in $\mathrm{m}^{3}, \mathrm{~N}(\mathrm{~g})$ is the monatomic nitrogen content in the arc plasma in atmospheres, $N_{\text {steel }}$ is the final nitrogen concentration in the solidified WM in wt \%, and $K$ is the apparent equilibrium constant for reaction Equation (1).

The molten pool volume during welding $(V)$ in $\mathrm{m}^{3}$ is calculated according to $[35,36]$ :

$$
V=\frac{\pi}{6} h\left(3\left(\frac{L}{2}\right)^{2}+h^{2}\right)
$$

where $h$ is the penetration depth in meter measured on the cross-section perpendicular to the weld seam and $L$ is the molten pool length during welding in meter, determined by the axis of the ellipsoid in the welding direction as seen in Figure 2.

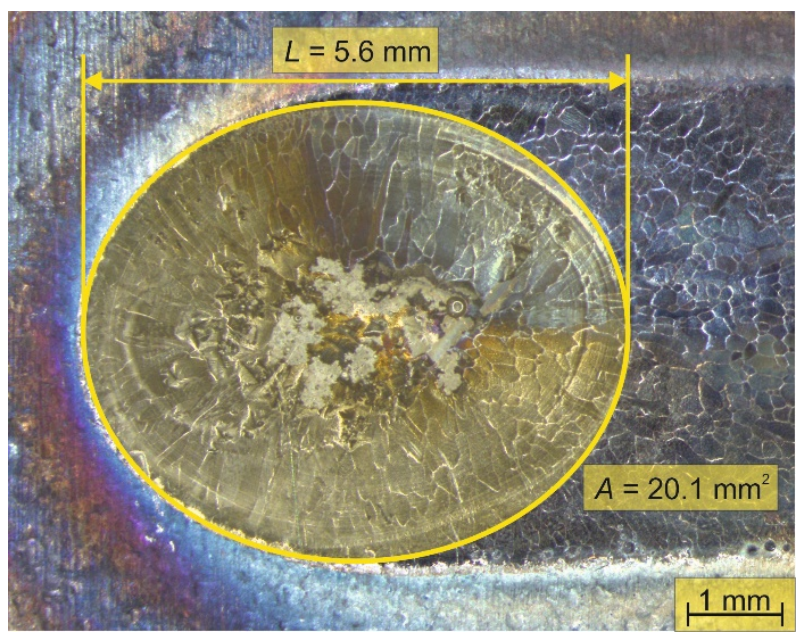

Figure 2. Determination of the molten pool surface $(A)$ during welding on the end crater surface. Arc energy: $0.53 \mathrm{~kJ} \cdot \mathrm{mm}^{-1}$, shielding gas: 100 vol. \% Ar.

About the $K_{a}$ reaction rate constant, very limited data are available in the professional literature. As shown by $[35,36], K_{a}$ has a weak dependency on the chemical composition, and its average value for DSS is taken as:

$$
K_{a}=3.5 \cdot 10^{4}\left(\mathrm{~kg} \cdot \mathrm{m}^{-2} \cdot \mathrm{s}^{-1} \cdot \mathrm{atm}^{-1}\right) .
$$

The density of the molten pool at the welding temperature, $\rho$ in $\mathrm{kg} \cdot \mathrm{m}^{-3}$ [42]:

$$
\rho=1000\left(-7.2 \cdot 10^{-4}\left(T-T_{m}\right)+7.04\right),
$$


where $T$ is the estimated molten pool temperature in Kelvin [36]:

$$
T=1995(K),
$$

and $T_{m}$ is the liquidus temperature for DSS 2205 in Kelvin [35]:

$$
T_{m}=1733(\mathrm{~K}) .
$$

The monatomic nitrogen content in the arc plasma $N(g)$ in atmosphere according to $[43,44]$ :

$$
N(g)=\sqrt{P_{N 2}} \exp \left(-\frac{\Delta G^{\circ} 1}{R T_{d}}\right)
$$

where $P_{N 2}$ is the partial pressure of the inlet gas in atmosphere [36]:

$$
P_{N 2}=\frac{N_{2}}{100} \text {. }
$$

$\Delta G^{0}{ }_{1}$ is the standard free energy for the reaction:

$$
\frac{1}{2} N_{2} \rightarrow N(g)
$$

and $\Delta G^{0}{ }_{1}$ in $\mathrm{J} \cdot \mathrm{mol}^{-1}$ according to $[35,44]$ is equal to:

$$
\Delta G^{\circ}{ }_{1}=362560-65.56 T_{d}
$$

where $T_{d}$ is the dissociation temperature of diatomic to monatomic nitrogen (Equation (10)) in Kelvin [35,44]:

$$
T_{d}=1995(\mathrm{~K}) .
$$

The universal gas constant, $R$ in $\mathrm{J} \cdot \mathrm{K}^{-1} \mathrm{~mol}^{-1}$ is equal to:

$$
R=8.314\left(\mathrm{~J} \cdot \mathrm{K}^{-1} \cdot \mathrm{mol}^{-1}\right) .
$$

The apparent equilibrium constant for reaction Equation (1), $K$, can be calculated [35]:

$$
K=\frac{\sqrt{K^{\prime}}}{K_{1}}
$$

where $K^{\prime}$ is the apparent equilibrium constant for the desorption reaction and according to Du Toit [35] equals to:

$$
K^{\prime}=\frac{\left(N_{e q}\right)^{2}}{P_{N 2}} .
$$

The $N_{e q}$ is the equilibrium nitrogen content of the molten metal (in wt \%) at the weld pool temperature for equilibrium with the nitrogen in the shielding gas, and calculated according to Wada et al. [45]:

$$
\log \left(\underline{N}_{e q}\right)=-\frac{247}{T}-1,22-\left(\frac{4780}{T}-1,51\right) \log f_{N, T}-\left(\frac{1760}{T}-0,91\right)\left(\log f_{N, T}\right)^{2},
$$

where $f_{N, T}$ is the nitrogen activity coefficient at a certain temperature in Kelvin. At this point, the previous models of [35,36] are modified. For the calculation of $N_{\text {eq }}$, Du Toit [35] and Wada et al. [45] calculated with $f_{N, 1873}$, which is the activity coefficient described for 1873 Kelvin not for the molten pool temperature T. Rokanopoulou et al. [36] changed the activity coefficient to the molten pool 
temperature, based on two different calculations of the equilibrium nitrogen content of the molten metal, $N_{e q}$. According to the conclusions of Rokanopoulou et al. [36], the $f_{N, T}$ increased to 0.161 from $f_{N, 1873}=0.134$. However, the nitrogen activity coefficient in case of DSS should decrease at the molten pool temperature compared to the 1873 Kelvin value [31]. Kobayashi et al. [46] showed that above the melting temperature, the nitrogen activity is decreasing in the case of stainless steels. Anson et al. [47] showed that although nitrogen activity is increasing over the melting temperature in the case of pure iron, the main alloying elements of DSS, such as chromium, nickel, manganese, and molybdenum, are all decreasing this activity in the molten state.

Therefore, in our model, the $f_{N, T}$ is calculated according to [48]:

$$
\log f_{N, T}=\left(\frac{2538}{T}-0.355\right) \log f_{N, 1873}
$$

which gives smaller value for the estimated molten pool temperature, $T$. The activity coefficient of nitrogen for 1873 Kelvin temperature [49]:

$$
\begin{aligned}
& \log f_{N, 1873}=e_{N}{ }^{N o} \% N+e_{N}{ }^{M n} \% M n+e_{N}{ }^{S i} \% S i+e_{N}{ }^{P} \% P+e_{N} C r \% C r+ \\
& +e_{N} M o \% M o+e_{N} N i \% N i+\left(\gamma_{N} C r \% C r^{2}+\gamma_{N} M n \% M n^{2}+\gamma_{N}{ }^{M o} \% M o^{2}+\gamma_{N}{ }^{N i} \% N i^{2}\right)
\end{aligned}
$$

where $e_{N}{ }^{X}$ are the first order and $\gamma_{N}{ }^{X}$ are the second order interaction parameters (Table 2) of nitrogen activity for a certain initial alloying element in the base material $\% X$ in $w t \%$, as can be seen in Table 1 .

\begin{tabular}{|c|c|c|}
\hline Alloying Element ${ }^{(X)}$ & $e_{N}^{X}$ & $\gamma_{N}{ }^{X}$ \\
\hline $\mathrm{N}$ & 0.130 & - \\
\hline $\mathrm{Mn}$ & -0.024 & $3.2 \times 10^{-5}$ \\
\hline $\mathrm{Si}$ & 0.043 & - \\
\hline $\mathrm{P}$ & 0.048 & - \\
\hline $\mathrm{Cr}$ & -0.048 & $3.5 \times 10^{-4}$ \\
\hline Mo & -0.013 & $7.9 \cdot \times 10^{-5}$ \\
\hline $\mathrm{Ni}$ & 0.011 & $3.5 \times 10^{-5}$ \\
\hline
\end{tabular}

Table 2. First $e_{N}{ }^{X}$ and second $\gamma_{N}{ }^{X}$ order interaction parameters for nitrogen activity of a certain alloying element at 1873 Kelvin [49].

Continuing Equation (14), $K_{1}$ is the equilibrium constant for nitrogen dissociation Equation (10), and according to Du Toit [35], it is equal to:

$$
K_{1}=\frac{N(g)}{\sqrt{P_{N 2}}}
$$

Knowing these values, the dissolved atomic nitrogen in the molten pool, over time, Equation (2) can be calculated for the reaction of Equation (1).

\subsection{Nitrogen Desorption into the Arc Plasma}

One way of dissolved nitrogen $(\underline{N})$ desorption from the molten pool is recombining and forming diatomic $N_{2}$ in the arc plasma (Figure 1b):

$$
2 \underline{N}(\mathrm{wt} \%) \rightarrow N_{2}
$$

The desorption rate of Equation (20) over time can be expressed as [36]:

$$
\frac{d \underline{N}(w t \%)}{d t}=\frac{100 A K_{d}}{\rho V}\left(N_{\text {steel }}^{2}-N_{\text {eq.steel }}{ }^{2}\right),
$$


where $A$ is measured on the welds' surfaces (e.g., see Figure 2), and $V$ and $\rho$ are calculated previously according to Equations (3) and (5), respectively. $K_{d}$ is the rate constant for the reaction of nitrogen desorption from the weld pool to the arc atmosphere (Equation (20)) in $\left(\mathrm{kg} \cdot \mathrm{m}^{-2} \cdot \mathrm{s}^{-1}(\mathrm{wt} \%)^{-2}\right)$, and according to $\mathrm{Du}$ Toit [35], it is equal to:

$$
K_{d}=\frac{10^{(-6340 / T+1.85)}}{1+130 f_{S} \% S}
$$

where $T$ is in Equation (6), \%S is the initial sulfur content in the base material (Table 1), and $f_{S}$ is the activity coefficient of sulfur in stainless steels, according to [50], calculated by:

$$
\log f_{S}=\% \operatorname{Cr}\left(-\frac{94.2}{T}+0.040\right)
$$

where $\% \mathrm{Cr}$ is the initial chromium content in the base material (Table 1). The nitrogen concentration in the weld pool for equilibrium with the nitrogen in the gas $N_{\text {eq.steel }}$ can be calculated according to Rokanopoulou [36]:

$$
N_{\text {eq.steel }}=\frac{\sqrt{P_{N 2}} \cdot \exp \left(-\frac{\Delta G^{\circ}}{R T}\right)}{f_{N, T}},
$$

where $P_{N 2}$ (Equation (9)), $T$ (Equation (6)), $R$ (Equation (13)), $f_{N, T}$ (Equation (17)) are already given, and $\Delta G^{0}{ }_{2}$ in $\mathrm{J} \cdot \mathrm{mol}^{-1}$ according to [51] is equal to:

$$
\Delta G_{2}^{\circ}=3598.2+23.89 \cdot T \text {. }
$$

Knowing these values, the nitrogen desorption to the arc plasma over time Equation (21) can be calculated for the reaction of Equation (20).

\subsection{Nitrogen Absorption from the Base Metal}

The rate of $\underline{N}$ absorption to the molten pool from the base metal (Figure 1c) is proportional to the melting rate and can be expressed as $[35,36]$ :

$$
\frac{d \underline{N}(w t \%)}{d t}=\% N\left(\frac{v}{L}\right)
$$

where $\% N$ is the initial nitrogen content in the base metal (Table 1), the length of the molten pool $L$ is seen in Figure 2, and $v$ is the welding speed in $\mathrm{m} \cdot \mathrm{s}^{-1}$.

\subsection{Nitrogen Desorption to the Base Metal}

The second way of $\underline{N}$ desorption to the base metal is during the solidification of molten pool at the rear of the weld pool (Figure 1d). Note that, as can be seen in Figure 1, $\underline{N}$ desorption takes place toward the solidified WM. For this reason, the actual measured total dissolved nitrogen content in the $\mathrm{WM}\left(N_{\text {steel }}\right)$ can be higher than what was predicted by the theoretical model. The nitrogen desorption to the base metal can be expressed according to $[35,36]$ :

$$
\frac{d \underline{N}(w \mathrm{t} \%)}{d t}=-N_{\text {steel }}\left(\frac{v}{L}\right) \text {. }
$$

All the expressions in Equation (27) are prescribed earlier.

Solving the theoretical model described here will result in the total amount of dissolved atomic nitrogen in the solidified WM $\left(N_{\text {steel }}\right)$. The basic assumption of the solution is that during steady state, the absorption and desorption processes are in equilibrium with each other (processes (a) $+(c)=(b)+$ (d) in Figure 1) and from this equilibrium, $N_{\text {steel }}$ can be expressed. This model also takes the nitrogen transport to and from the molten pool towards the base metal into account (processes (c) and (d) in 
Figure 1), which was proven to be true by Hosseini and Karlsson [52]. It is worth mentioning nitrogen desorption from the heat-affected zone was not observed during solid-state reheating in Gleeble ${ }^{\circledR}$ simulations [53], with relatively fast 1200 to $800^{\circ} \mathrm{C}$ cooling rates $\left(50{ }^{\circ} \mathrm{C} \cdot \mathrm{s}^{-1}\right)$.

\section{Results and Discussion}

In the first section, the results of the effects of shielding gasses nitrogen $\left(N_{2}\right)$ content on the arc voltage are discussed. Afterwards, the comparison of our improved theoretical model to the measured total dissolved nitrogen in the WM $\left(N_{\text {steel }}\right)$ values of autogenous welds is evaluated. A comparison is also made between the improved theoretical model and previously published models.

\subsection{Effects of Shielding Gas Nitrogen Content on the Arc Voltage}

To better evaluate the physical welding experiments during TIG welding, it was essential to keep the arc energy values at constant levels with the different nitrogen-containing shielding gases. Thus, the welding current ( $I$ in Amps) was always adjusted to the evolved arc voltage ( $U$ in Volts). The effects of shielding gas $\mathrm{N}_{2}$ content on the arc voltage can be seen in Figure 3.

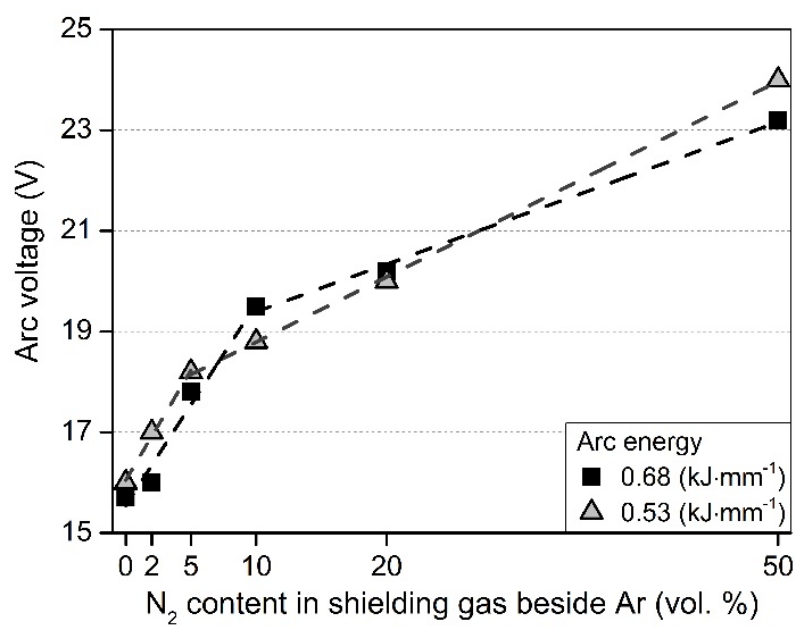

Figure 3. The effects of shielding gas $N_{2}$ content (mixed to Ar) on the arc voltage during TIG welding with a constant arc length of $2 \mathrm{~mm}$.

From Figure 3, it can be generally said that the arc voltage is increasing with the increasing $\mathrm{N}_{2}$ content in the shielding gas. The relationship between them is linear; however, the slope of the fitted line is changing in the 5 to $10 \mathrm{vol} . \% N_{2}$ range. In the case of lower $N_{2}$ levels, the slope of the fitted line is higher (the increase of the arc voltage is more significant), $\sim 0.42$ (see Table 3 ). In the case of higher $\mathrm{N}_{2}$ levels, the slope is lower, $\sim 0.11$. The breakpoint of the slopes is different in the case of the two arc energies: 10 vol. $\% N_{2}$ in the case of $0.68 \mathrm{~kJ} \cdot \mathrm{mm}^{-1}$ and 5 vol. $\% N_{2}$ in the case of $0.53 \mathrm{~kJ} \cdot \mathrm{mm}^{-1}$. The possible reason for the arc voltage change with the $N_{2}$ content is the different thermal conductivity and ionization energy, compared to Ar.

This observation has practical importance, because this is the $N_{2}$ content range, where shielding gases are used for DSS TIG welding. Moreover, many researchers [23,24,54] observed sometimes contradictory results of $\gamma$ content in the WM, using this shielding gas range for TIG welding, which could originate from this effect of the arc voltage changes.

To keep the arc energies constant with a constant welding speed of $3 \mathrm{~mm} \cdot \mathrm{s}^{-1}$, the welding currents were adjusted to each case, as can be seen in Table 4 . 
Table 3. Constants of the linearly fitted lines over the arc voltage values in the different shielding gas $\mathrm{N}_{2}$ ranges (Figure 3).

\begin{tabular}{|c|c|c|c|}
\hline Arc Energy & $\begin{array}{l}\text { Shielding Gas } N_{2} \\
\text { Range (beside Ar) }\end{array}$ & \multirow{2}{*}{$\begin{array}{c}\text { Correlation between Arc } \\
\text { Voltage and Shielding Gas } \\
N_{2} \text { Content }\end{array}$} & \multirow{2}{*}{$\begin{array}{l}\mathbf{R}^{2} \text { of the } \\
\text { Correlation (-) }\end{array}$} \\
\hline$\left(\mathrm{kJ} \cdot \mathrm{mm}^{-1}\right)$ & (vol. \%) & & \\
\hline \multirow{2}{*}{0.68} & $1-10$ & $\mathrm{U}=15.5+0.40 \cdot \mathrm{N}_{2}$ & 0.97 \\
\hline & $10-50$ & $\mathrm{U}=18.5+0.09 \cdot \mathrm{N}_{2}$ & 0.99 \\
\hline \multirow{2}{*}{0.53} & $1-5$ & $\mathrm{U}=16.1+0.44 \cdot N_{2}$ & 0.99 \\
\hline & $5-50$ & $\mathrm{U}=17.5+0.13 \cdot \mathrm{N}_{2}$ & 0.99 \\
\hline
\end{tabular}

Table 4. The adjusted welding current with the arc voltage values in order to keep constant arc energies with constant welding speed of $3 \mathrm{~mm} \cdot \mathrm{s}^{-1}$.

\begin{tabular}{|c|c|c|c|}
\hline Arc Energy & $\begin{array}{c}\text { Shielding Gas } N_{2} \\
\text { Content (beside Ar) }\end{array}$ & Welding Current & Arc Voltage \\
\hline$\left(\mathrm{kJ} \cdot \mathrm{mm}^{-1)}\right.$ & (vol. \%) & (A) & (V) \\
\hline \multirow{6}{*}{0.68} & 0 & 130 & 15.7 \\
\hline & 2 & 128 & 16.0 \\
\hline & 5 & 115 & 17.8 \\
\hline & 10 & 105 & 19.5 \\
\hline & 20 & 101 & 20.2 \\
\hline & 50 & 88 & 23.2 \\
\hline \multirow{6}{*}{0.53} & 0 & 100 & 16.0 \\
\hline & 2 & 94 & 17.0 \\
\hline & 5 & 88 & 18.2 \\
\hline & 10 & 85 & 18.8 \\
\hline & 20 & 80 & 20.0 \\
\hline & 50 & 67 & 24.0 \\
\hline
\end{tabular}

\subsection{Weld Geometry Results}

The molten pool surface and volume values are calculated with the solidified WM geometries, as described in Section 3.1, according to Figure 2 and Equation (3). The results are listed in Table 5.

Table 5. The calculated average molten pool geometries measured on the solidified WM.

\begin{tabular}{|c|c|c|c|c|c|}
\hline Arc Energy & $\begin{array}{c}\text { Shielding Gas } \\
\mathrm{N}_{2} \text { Content } \\
\text { (beside Ar) }\end{array}$ & $\begin{array}{c}\text { Calculated } \\
\text { Average } \\
\text { Molten Pool } \\
\text { Surface, } A\end{array}$ & $\begin{array}{l}\text { Calculated } \\
\text { Average } \\
\text { Molten Pool } \\
\text { Length, } L\end{array}$ & $\begin{array}{c}\text { Average } \\
\text { Penetration } \\
\text { Depth, } h\end{array}$ & Volume, $V$ \\
\hline$\left(\mathrm{kJ} \cdot \mathrm{mm}^{-1)}\right.$ & (vol. \%) & $\left(\mathrm{mm}^{2)}\right.$ & $(\mathrm{mm})$ & $(\mathrm{mm})$ & $\left(\mathrm{mm}^{3}\right)$ \\
\hline \multirow{6}{*}{0.68} & 0 & 40.2 & 8.1 & 1.2 & 51.8 \\
\hline & 2 & 42.0 & 8.2 & 1.2 & 53.3 \\
\hline & 5 & 42.3 & 8.4 & 1.2 & 56.3 \\
\hline & 10 & 43.1 & 8.4 & 1.3 & 58.8 \\
\hline & 20 & 43.9 & 8.8 & 1.4 & 69.5 \\
\hline & 50 & 46.6 & 9.2 & 1.6 & 75.4 \\
\hline \multirow{6}{*}{0.53} & 0 & 20.1 & 5.6 & 0.4 & 11.2 \\
\hline & 2 & 21.9 & 5.7 & 0.7 & 12.5 \\
\hline & 5 & 22.5 & 6.0 & 0.9 & 15.6 \\
\hline & 10 & 24.8 & 6.1 & 1.1 & 15.9 \\
\hline & 20 & 25.3 & 6.2 & 1.1 & 19.8 \\
\hline & 50 & 30.9 & 6.3 & 1.5 & 20.8 \\
\hline
\end{tabular}


From Table 5, it can be clearly seen that although the arc energies were kept constant, the increasing $\mathrm{N}_{2}$ content in the shielding gas means increasing amount of heat during TIG welding, which is represented in the increasing values of WM geometries. This observation was taken into account during the solution of the theoretical model in Equations (2), (21), (26), and (27).

\subsection{Comparison of the Physical and Theoretical Model of the Total Dissolved Nitrogen Content in the Solidified Weld Metal}

The comparison of the theoretical and physical model (with measured nitrogen contents) of the $N_{\text {steel }}$ values can be seen in Figure 4.

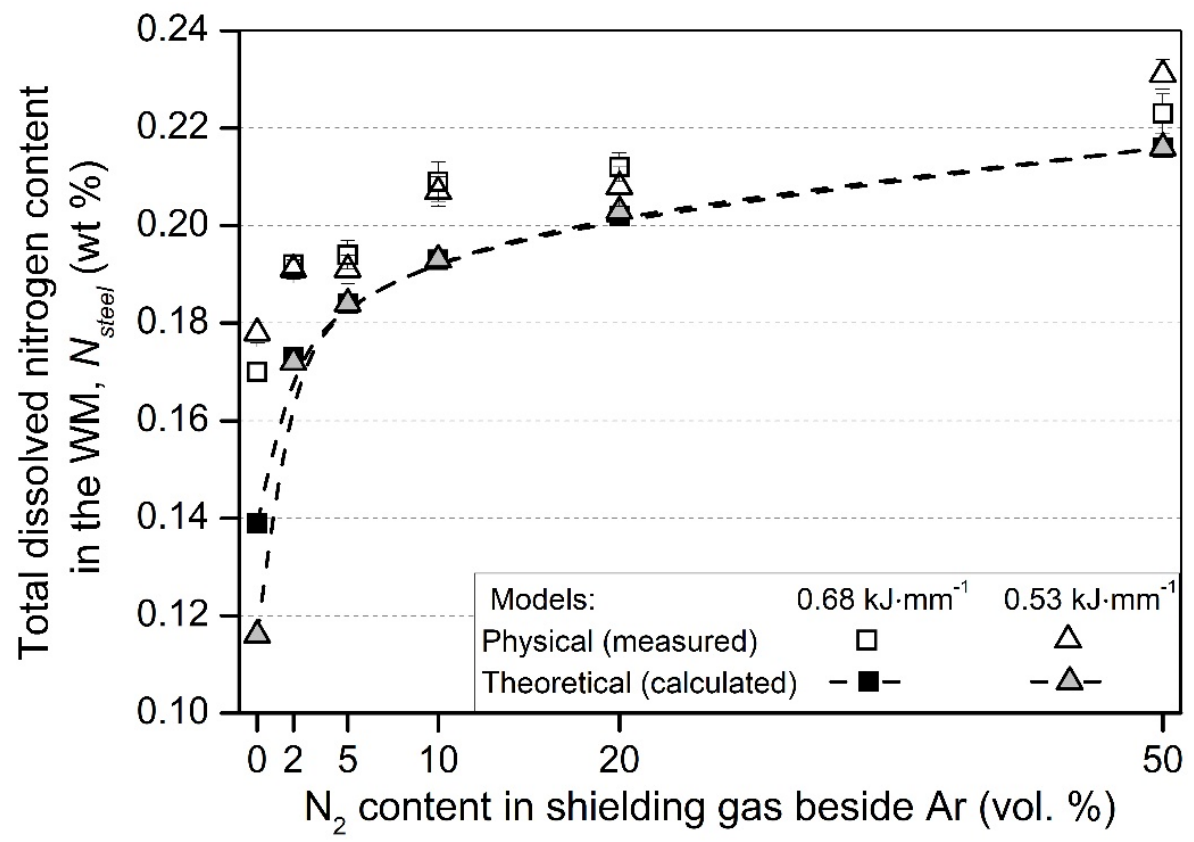

Figure 4. The comparison of the physical (measured) and theoretical (calculated) models of the dissolved total nitrogen in the WM $\left(N_{\text {steel }}\right)$.

From Figure 4, the following conclusion can be drawn. The calculated values, according to the developed theoretical model, gives smaller $N_{\text {steel }}$ values than the measured. This can be explained as that the theoretical model calculates the molten pool $\underline{N}$ content during welding and does not take into account the $\underline{N}$ leaving the molten pool toward the previously solidified WM (Figure 1d). The samples for $N_{\text {steel }}$ content HORIBA measurements were machined out from the solidified weld metal, and thus, higher values could have been measured for the actual $N_{\text {steel }}$ content. Further, in the applied arc energy range $\left(0.53-0.68 \mathrm{~kJ} \cdot \mathrm{mm}^{-1}\right)$, the theoretical model does not result in significant differences between the $N_{\text {steel }}$ values for a certain $N_{2}$ shielding gas composition. However, the measured values show larger differences between the two arc energies, which originates from the non-equilibrium behavior of arc welding, but no clear relationship can be found between the arc energy and the $N_{\text {steel }}$ values on case of nitrogen-containing shielding gases. In case of TIG welding with pure Ar shielding gas, a higher $N_{\text {steel }}$ content was measured in the case of smaller arc energy. This observation complies with the results of Hosseini et al. [37], who showed that the total dissolved nitrogen content is decreasing with the increasing arc energy in the case of autogenous TIG welding with Ar gas shielding. The reason for this is the increasing molten pool surface and volume with the increasing arc energy (Table 5); thus, more $\underline{N}$ can leave the molten pool through desorption to the arc atmosphere and to the base metal. This phenomenon is not emphasized enough in our and the previously developed theoretical models. Figure 4 also shows that the highest increase in the $N_{\text {steel }}$ is significantly pronounced in the $2-10$ vol. $\% N_{2}$ shielding gas range (compared to the samples welded in pure Ar), and this is exactly 
the range where most of the argon + nitrogen shielding gas mixtures are used in industrial applications. This observation is in correlation with the significant increase of arc voltage in this shielding gas $N_{2}$ content range (Figure 3). At higher $N_{2}$ levels of shielding gas, the solubility limit of $\underline{N}$ restrains the significant $N_{\text {steel }}$ increase.

In order to reach the initial nitrogen content of the $\mathrm{BM}(\% \mathrm{~N}=0.181 \mathrm{wt} \%)$ in the solidified WM, approx. 2 vol. \% $N_{2}$ content in the shielding gas should be used according to the physical model and approx. 5 vol. $\% N_{2}$ according to the theoretical model. This also complies with the industrial practice, where these nitrogen-containing gas mixtures tend to be used to prevent nitrogen loss from the molten pool. Table 6 shows the comparison of the measured $N_{\text {steel }}$ values to our improved theoretical model and to Du Toit's model [35].

Table 6. Comparison of the measured $N_{\text {steel }}$ values to our improved theoretical model and to Du Toit's model [35].

\begin{tabular}{|c|c|c|c|c|c|c|}
\hline \multirow{2}{*}{ Arc Energy } & \multirow{2}{*}{$\begin{array}{c}\text { Shielding } \\
\text { Gas } N_{2} \\
\text { Content } \\
\text { (beside Ar) }\end{array}$} & \multirow{2}{*}{$\begin{array}{c}\text { Measured } \\
\text { Average } \\
N_{\text {steel }}\end{array}$} & \multicolumn{4}{|c|}{ Calculated Nitrogen Content of the WM $\left(N_{\text {steel }}\right)$} \\
\hline & & & $\begin{array}{c}\text { Our } \\
\text { Model }\end{array}$ & $\begin{array}{c}\text { Error of Our } \\
\text { Model to the } \\
\text { Measured } N_{\text {steel }}\end{array}$ & $\begin{array}{l}\text { Du Toit's } \\
\text { [35] Model }\end{array}$ & $\begin{array}{c}\text { Error of Du } \\
\text { Toit's Model } \\
\text { [35] }\end{array}$ \\
\hline$\left(\mathrm{kJ} \cdot \mathrm{mm}^{-1}\right)$ & (vol. \%) & (wt \%) & (wt \%) & $(\%)$ & (wt \%) & $(\%)$ \\
\hline \multirow{6}{*}{0.68} & 0 & 0.170 & 0.139 & 18.2 & 0.097 & 42.9 \\
\hline & 2 & 0.192 & 0.173 & 9.9 & 0.137 & 28.6 \\
\hline & 5 & 0.194 & 0.184 & 5.2 & 0.156 & 19.6 \\
\hline & 10 & 0.209 & 0.193 & 7.7 & 0.174 & 16.7 \\
\hline & 20 & 0.212 & 0.202 & 4.7 & 0.197 & 7.1 \\
\hline & 50 & 0.223 & 0.216 & 3.1 & 0.237 & 6.3 \\
\hline \multirow{6}{*}{0.53} & 0 & 0.178 & 0.116 & 34.8 & 0.074 & 58.4 \\
\hline & 2 & 0.191 & 0.172 & 9.9 & 0.135 & 29.3 \\
\hline & 5 & 0.191 & 0.184 & 3.7 & 0.156 & 18.3 \\
\hline & 10 & 0.207 & 0.193 & 6.8 & 0.174 & 15.9 \\
\hline & 20 & 0.208 & 0.203 & 2.4 & 0.197 & 5.3 \\
\hline & 50 & 0.231 & 0.216 & 6.5 & 0.237 & 2.6 \\
\hline
\end{tabular}

In the case of Ar shielding, according to the relationship between the arc energy and the $N_{\text {steel }}$ value developed by Hosseini et al. [55], the $N_{\text {steel }}$ for $0.53 \mathrm{~kJ} \cdot \mathrm{mm}^{-1}$ arc energy is predicted to be $0.165 \mathrm{wt} \%$, and $0.160 \mathrm{wt} \%$ for $0.68 \mathrm{~kJ} \cdot \mathrm{mm}^{-1}$ arc energy. These predictions are closer to our measured values ( 0.178 and $0.170 \mathrm{wt} \%$, respectively) than those calculated by the improved model ( 0.116 and $0.139 \mathrm{wt} \%)$. The possible reason for this is that the nitrogen transport from the high temperature heat-affected zone (HTHAZ) to the molten pool [52] has much higher importance in the case of the non-equilibrium conditions during arc welding than expected in the developed nitrogen kinetic models. This $\underline{N}$ absorption forms the HTHAZ results in higher $N_{\text {steel }}$ values in the solidified WM. In the further development of our improved model, this observation should be taken into consideration in the future. In the case of the nitrogen-containing gas mixtures, our improved model gives less than $10 \%$ error to the measured total dissolved nitrogen $\left(N_{\text {steel }}\right)$ values in all cases. For DSS autogenous TIG welding with nitrogen-containing shielding gas, our improved model gives better prediction on the $N_{\text {steel }}$ values (except one case) than the previously developed model by Du Toit [35], which was originally set up for austenitic stainless steels. The model developed by Rokanopoulou et al. [36] was not evaluated in detail in this paper, because their model can sometimes result in exaggerated values. For example, according to their model [36], applying the welding conditions: welding current $80 \mathrm{~A}$, welding speed $3 \mathrm{~mm} \cdot \mathrm{s}^{-1}$, and $\mathrm{Ar}+5 \mathrm{vol} . \% N_{2}$ shielding gas will result in $1.19 \mathrm{wt} \%$ predicted $N_{\text {steel }}$ value in the case of plasma arc welding of DSS 2205. This is over the solubility limit of nitrogen in $\gamma$ (which has about one magnitude higher solubility of nitrogen than $\delta$ has) [31].

In Figure 5, it can be seen that our improved model approximates the measured values better than the other models. Figure 6 shows metallographic images taken from the WM, welded with Ar, and $2-50$ vol. $\% N_{2}$ shielding gases. 


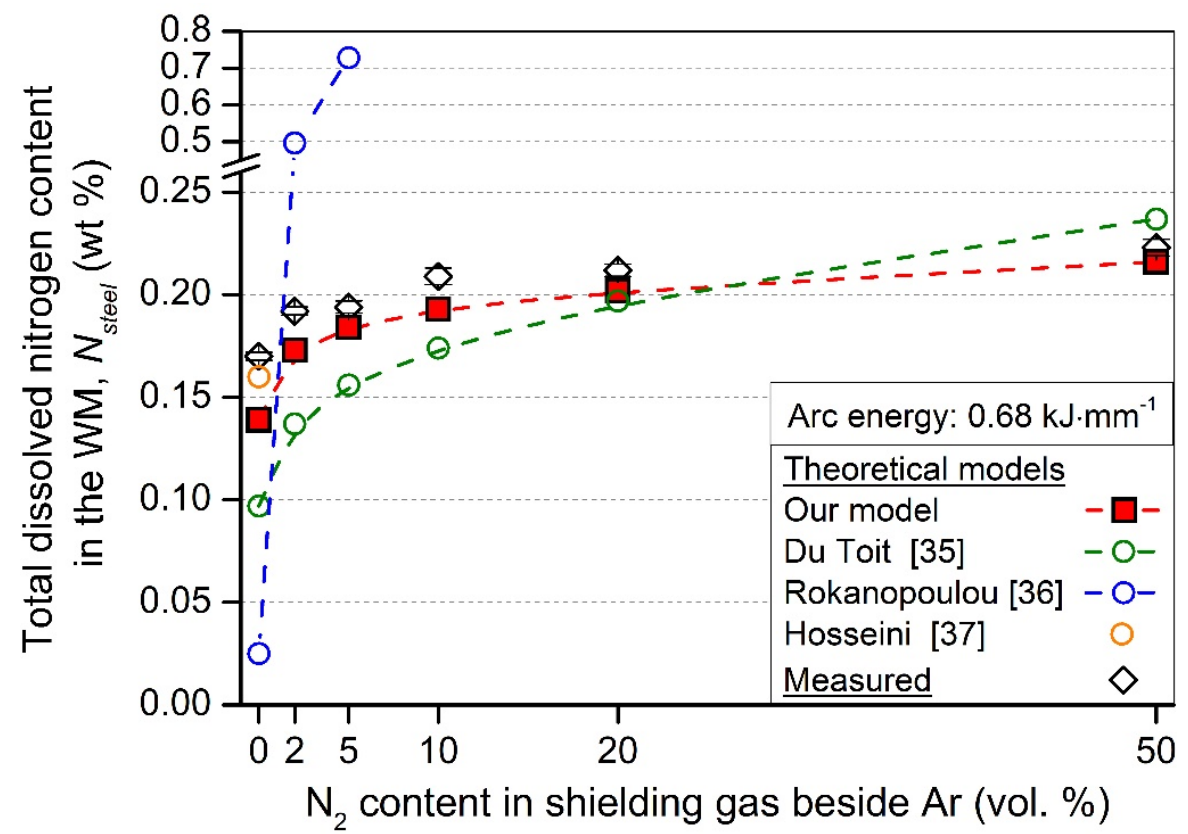

Figure 5. The comparison of the different theoretical models and the measured $N_{\text {steel }}$ values of the weld metals in the case of the $0.68 \mathrm{~kJ} \cdot \mathrm{mm}^{-1}$ arc energy.

Weld metal microstructures with $0.68 \mathrm{~kJ} \mathrm{~mm}^{-1}$ arc energy and different shielding gas $\mathrm{N}_{2}$ contents

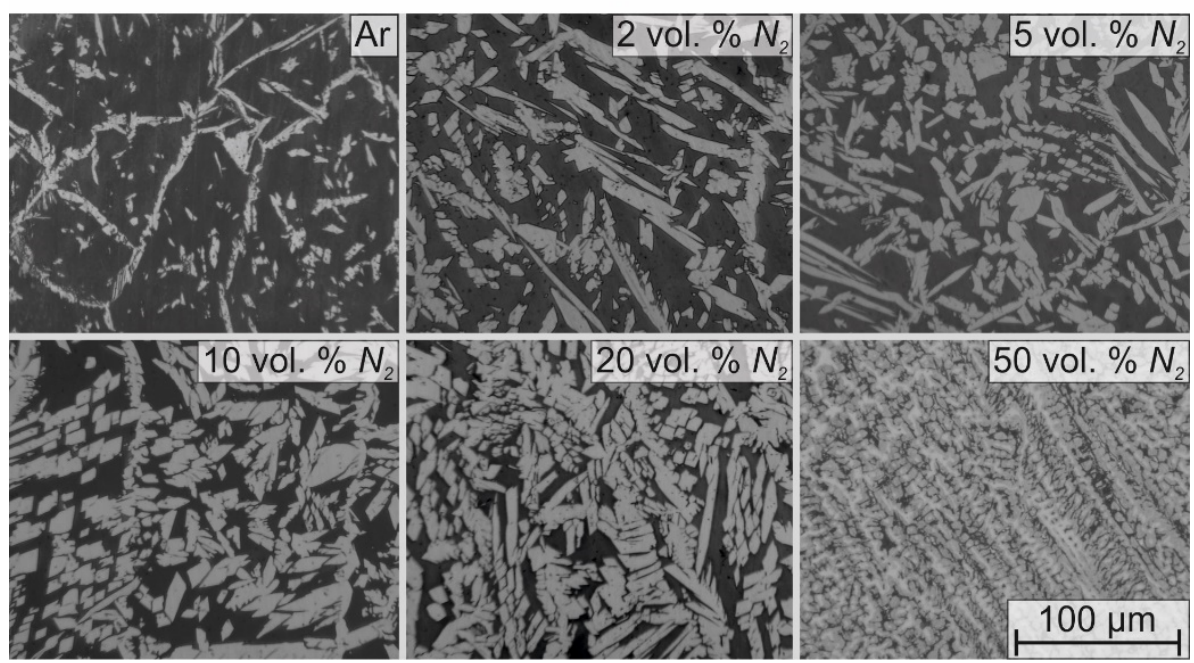

Figure 6. Metallographic images of weld metal microstructures, TIG welded with constant $0.68 \mathrm{~kJ} \cdot \mathrm{mm}^{-1}$ arc energy and different nitrogen containing shielding gases.

The corresponding average $\gamma$ contents (light areas) are 16.0\%, 34.5\%, 43.6\%, 52.1\%, 67.1\%, and $71.4 \%$, respectively. The Ar welded sample shows highly ferritic microstructure in the WM. In this case, coherent $\gamma$ grains can be seen in the $\delta$ grain boundaries. In addition to this, intergranular $\gamma$ islands can be found inside the $\delta$ grains. The $2-5$ vol. $\% N_{2}$ addition to the shielding gas increased the $\gamma$ content in the WM, as the $N_{\text {steel }}$ also increased (from 0.170 to 0.192 and $0.194 \mathrm{wt} \%$, respectively). In these cases, the intergranular $\gamma$ grains are connected to the grain boundary $\gamma$ grains. The $10 \mathrm{vol} . \%$ $\mathrm{N}_{2}$ addition to the shielding gas results in more austenitic microstructure (52.1\% $\gamma$ content) and also a significant increase in the $N_{\text {steel }}$ to $0.209 \mathrm{wt} \%$. This is the shielding gas composition, where a breakpoint was found in the corresponding arc voltage (Figure 3 and Table 3 ). The 20 vol. $\% N_{2}$ addition to the 
shielding gas resulted only in a small increase in $N_{\text {steel }}(0.212 \mathrm{wt} \%)$, compared to the $10 \mathrm{vol} . \% \mathrm{~N}_{2}$ shielding gas, but a high increase in the $\gamma$ content $(67.1 \%)$. The 50 vol. $\% N_{2}$ addition to the shielding gas resulted in eutectic $\delta+\gamma$ solidification from the liquid phase. In this case, interdentritic $\delta$ grains can be seen inside the $\gamma$ matrix. As a summary, it can be said that the $N_{\text {steel }}$ value depends on the $N_{2}$ content of the applied shielding gas, and the austenite content in the WM depends on the $N_{\text {steel }}$.

\section{Conclusions}

In this study, the autogenous tungsten inert gas (TIG) welding of DSS 2205 type duplex stainless steel was done using different argon (Ar) and $\mathrm{Ar}+$ nitrogen $\left(N_{2}\right)$ shielding gas mixtures at two different $\left(0.53\right.$ and $\left.0.68 \mathrm{~kJ} \cdot \mathrm{mm}^{-1}\right)$ arc energies. We determined the effects of nitrogen addition to the shielding gas to the arc voltage and to the total dissolved nitrogen $\left(N_{\text {steel }}\right)$ content in the solidified weld metal (WM). Further, an improved theoretical was established to predict the $N_{\text {steel }}$ content in the WM. According to our results, the following conclusions can be drawn:

- During TIG welding, the arc voltage is increasing linearly with the increasing $\mathrm{N}_{2}$ content in the Ar shielding gas. The slope of this linear relationship is different in the 5 to $10 \mathrm{vol} . \% \mathrm{~N}_{2}$ range. The breakpoint of the slopes is different in the case of the two arc energies: $10 \mathrm{vol} . \% \mathrm{~N}_{2}$ in case of $0.68 \mathrm{~kJ} \cdot \mathrm{mm}^{-1}$ and $5 \mathrm{vol} . \% \mathrm{~N}_{2}$ in case of $0.53 \mathrm{~kJ} \cdot \mathrm{mm}^{-1}$.

- The higher arc energy (larger molten pool surface and volume) resulted in less $N_{\text {steel }}$ content in the WM in the case of the Ar welded samples; $0.178 \mathrm{wt} \%$ for $0.53 \mathrm{~kJ} \cdot \mathrm{mm}^{-1}$ and $0.170 \mathrm{wt} \%$ for $0.53 \mathrm{~kJ} \cdot \mathrm{mm}^{-1}$.

- The increase in the $N_{\text {steel }}$ is significantly pronounced in the $2-10$ vol. $\% N_{2}$ shielding gas range (compared to the Ar welded samples), where most of the $\mathrm{Ar}+\mathrm{N}_{2}$ shielding gas mixtures are used in industrial applications. This observation is in correlation with the significant increase of arc voltage in this shielding gas $\mathrm{N}_{2}$ content range.

- Our improved theoretical model, established for the $N_{\text {steel }}$ prediction, results in less than $10 \%$ error compared to the measured $N_{\text {steel }}$ values in case of autogenous TIG welding of DSS 2205 with $\mathrm{Ar}+\mathrm{N}_{2}$ shielding gases.

- The 50 vol. $\% N_{2}$ addition to the Ar shielding gas resulted in eutectic ferrite + austenite solidification from the liquid phase.

With our improved model, the total dissolved nitrogen content in the weld metal can be predicted in the case of duplex stainless-steel autogenous welding after a simple welding trial. This prediction has practical importance, as the austenite content in the weld metal is in correlation with the dissolved nitrogen content. In the near future, this correlation will be investigated in more details, which is helpful for the welding design methodology for industrial applications.

Author Contributions: The contribution of authors can be explained as below according to CRediT Taxonomy of contributor roles. Conceptualization, validation, resources, writing-original draft preparation, writing-review and editing, visualization, B.V. and K.M.; methodology, software, formal analysis, investigation, data curation, B.V.; supervision, project administration, funding acquisition, K.M.

Funding: This research has been supported by the János Bolyai Research Scholarship of the Hungarian Academy of Sciences grant number: BO/00196/16/6 and by the National Research, Development and Innovation Office-NKFIH, OTKA PD 120865 (K. Májlinger). The research reported in this paper was supported by the BME Nanotechnology FIKP grant of EMMI (BME FIKP-NAT).

Conflicts of Interest: The authors declare no conflict of interest.

\section{References}

1. Russo Spena, P.; Rossi, S.; Wurzer, R. Effects of Welding Parameters on Strength and Corrosion Behavior of Dissimilar Galvanized Q\&P and TRIP Spot Welds. Metals 2017, 7, 534.

2. Dobosy, Á.; Gáspár, M.; Lukács, J. The Influence of Mismatch Effect on the High Cycle Fatigue Resistance of High Strength Steel Welded Joints. Adv. Mater. Res. 2018, 1146, 73-83. [CrossRef] 
3. Béres, G.; Weltsch, Z. Estimation of Strength Properties from Microhardness Results in Dual Phase Steels with Different Martensite Volume Fraction. Period. Polytech. Transp. Eng. 2018, 47, 1-7. [CrossRef]

4. Palotas, B.; Pogonyi, T. Results of resistance spot welding of dual phase steels. In Proceedings of the Provisional agenda of the Commission III Intermediate Meeting 2017 (III-1784-17), Budapest, Hungary, 6-7 February 2017; Borhy, I., Wikhardt, P., dos Santos, J.F., Eds.; Magyar Hegesztési Egyesület: Budapest, Hungary, 2017. III-1794-17.

5. Boillot, P.; Peultier, J. Use of stainless steels in the industry: Recent and future developments. Procedia Eng. 2014, 83, 309-321. [CrossRef]

6. Soulignac, P. Celebrating the $70+$ years of duplex stainless steels in Europe. In Proceedings of the 8th Duplex Stainless Steels Conference, Beaune, France, 13-15 October 2010.

7. Chater, J. Playing to strength: Suplex gains market share in construction and transport. Stainl. Steel World 2017, 29, 28-32.

8. Świerczyńska, A.; Fydrych, D.; Rogalski, G. Diffusible hydrogen management in underwater wet self-shielded flux cored arc welding. Int. J. Hydrog. Energy 2017, 42, 24532-24540. [CrossRef]

9. Haldorsen, L.M. Welding duplex-challenges faced and experience gained. Stainl. Steel World 2016, 28, 53-58.

10. Chater, J. The year in stainless steel: Industry sees growth, but over-production still an issue. Stainl. Steel World 2019, 31, 28-31.

11. Rosemann, P.; Müller, C.; Baumann, O.; Modersohn, W.; Halle, T. Influence of the post-weld surface treatment on the corrosion resistance of the duplex stainless steel 1.4062. IOP Conf. Ser. Mater. Sci. Eng. 2017, 181, 012019. [CrossRef]

12. International Stainless Steel Forum (ISSF). Stainless Steel in Figures 2018; ISSF: Brussels, Belgium, 2018 ; p. 15.

13. Kotecki, D.J. Some pitfalls in welding of duplex stainless steels. Soldag. Insp. 2010, 15, 336-343. [CrossRef]

14. Gunn, R.N. Duplex Stainless Steels: Microstructure, Properties and Applications; Abington Publishing: Cambridge, UK, 1997; pp. 24-27.

15. Westin, E. Microstructure and Properties of Welds in the Lean Duplex Stainless Steel LDX 2101. Ph.D. Thesis, Royal Institute of Technology, Stackholm, Sweden, 2010.

16. Zucato, I.; Moreira, M.C.; Machado, I.F.; Lebrão, S.M.G. Microstructural Characterization and the Effect of Phase Transformations on Toughness of the UNS S31803 Duplex Stainless Steel Aged Treated at $850{ }^{\circ} \mathrm{C}$. Mater. Res. 2002, 5, 385-389. [CrossRef]

17. Alves, A.D.N.S.; Ferreira, D.M.B.; Martins, T.F.; José, G. Numerical Simulation of Welding Superduplex UNS S32760 Stainless Steel with the Flux Cored Arc Welding (FCAW) Process using Finite Element Method. In Proceedings of the XLII consolda-Congresso Nacional De Soldagem, Associacao Brasileira de Soldagem, Belo Horizonte, Brazil, 30 November 2016.

18. Yang, Y.; Guo, Y.; Liu, Y.; Li, J.; Jiang, Y. The Microstructure and Pitting Resistance of 2002 Lean Duplex Stainless Steel after the Simulated Welding Thermal Cycle Process. Materials 2018, 12, 70. [CrossRef] [PubMed]

19. Nilsson, J.-O. The role of nitrogen in duplex stainless steels. Stainl. Steel World 2016, 28, 26-27.

20. Ha, H.-Y.; Lee, C.-H.; Lee, T.-H.; Kim, S. Effects of Nitrogen and Tensile Direction on Stress Corrosion Cracking Susceptibility of Ni-Free FeCrMnC-Based Duplex Stainless Steels. Materials 2017, 10, 294. [CrossRef] [PubMed]

21. Alcantara, A.S.; Fábián, E.R.; Furkó, M.; Fazakas, É.; Dobránszky, J.; Berecz, T. Corrosion resistance of TIG welded joints of stainless steels. Mater. Sci. Forum 2017, 885, 190-195. [CrossRef]

22. Gennari, C.; Lago, M.; Bögre, B.; Meszaros, I.; Calliari, I.; Pezzato, L. Microstructural and Corrosion Properties of Cold Rolled Laser Welded UNS S32750 Duplex Stainless Steel. Metals 2018, 8, 1074. [CrossRef]

23. Başyiğit, A.; Kurt, A. The Effects of Nitrogen Gas on Microstructural and Mechanical Properties of TIG Welded S32205 Duplex Stainless Steel. Metals 2018, 8, 226. [CrossRef]

24. Sales, A.M.; Westin, E.M.; Jarvis, B.L. Effect of nitrogen in shielding gas of keyhole GTAW on properties of duplex and superduplex welds. Weld. World 2017, 61, 1133-1140. [CrossRef]

25. Westin, E.M.; Johansson, M.M.; Pettersson, R.F.A. Effect of nitrogen-containing shielding and backing gas on the pitting corrosion resistance of welded lean duplex stainless steel LDX $2101^{\circledR}$ (EN 1.4162, UNS S32101). Weld. World 2013, 57, 467-476. [CrossRef]

26. Allum, C. Nitrogen Absorption from Welding Arc; International Institue of Welding: Lisbon, Portugal, 1988. 
27. Pramanik, A.; Littlefair, G.; Basak, A.K. Weldability of Duplex Stainless Steel. Mater. Manuf. Process. 2015, 30, 1053-1068. [CrossRef]

28. Pickle, T.; Henry, N.; Morriss, P.; Tennis, L.; Wagner, D.; Baumer, R.E. Root Pass Microstructure in Super Duplex Stainless Steel Multipass Welds. Weld. J. 2019, 98, 123-134.

29. Dobranszky, J.; Szabo, P.J.; Berecz, T.; Hrotko, V.; Portko, M. Energy-dispersive spectroscopy and electron backscatter diffraction analysis of isothermally aged SAF 2507 type superduplex stainless steel. Spectrochim. Acta Part B At. Spectrosc. 2004, 59, 1781-1788. [CrossRef]

30. Knyazeva, M.; Pohl, M. Duplex Steels. Part II: Carbides and Nitrides. Metallogr. Microstruct. Anal. 2013, 2, 343-351. [CrossRef]

31. Lippold, J.C.; Kotecki, D.J. Welding Metallurgy and Weldability of Stainless Steels; John Wiley \& Sons, Inc.: Hoboken, NJ, USA, 2005; pp. 240-244.

32. Migiakis, K.; Papadimitriou, G.D. Effect of nitrogen and nickel on the microstructure and mechanical properties of plasma welded UNS S32760 super-duplex stainless steels. J. Mater. Sci. 2009, 44, 6372-6383. [CrossRef]

33. Valiente Bermejo, M.A.A.; Karlsson, L.; Svensson, L.-E.E.; Hurtig, K.; Rasmuson, H.; Frodigh, M.; Bengtsson, P. Effect of shielding gas on welding performance and properties of duplex and superduplex stainless steel welds. Weld. World 2015, 59, 239-249. [CrossRef]

34. Hertzman, S.; Charles, J. On the effect of nitrogen on duplex stainless steels. Rev. Métall. 2011, 108, 413-425. [CrossRef]

35. Du Toit, M. The Behaviour of Nitrogen during the Autogenous Arc Welding of Stainless Steel. Ph.D. Thesis, University of Pretoria, Hatfield, South Africa, 2001.

36. Rokanopoulou, A.; Skarvelis, P.; Papadimitriou, G.D. Welding design methodology for optimization of phase balance in duplex stainless steels during autogenous arc welding under $\mathrm{Ar}-\mathrm{N}_{2}$ atmosphere. Weld. World 2019, 63, 3-10. [CrossRef]

37. Hosseini, V.A. Super Duplex Stainless Steels-Microstructure and Properties of Physically Simulated Base and Weld Metal. Ph.D. Thesis, Univesity of West, Trollhattan, Sweden, 2018.

38. Putz, A.; Althuber, M.; Zelić, A.; Westin, E.M.; Willidal, T.; Enzinger, N. Methods for the measurement of ferrite content in multipass duplex stainless steel welds. Weld. World 2019, 63, 1075-1086. [CrossRef]

39. Hosseini, V.A.; Hurtig, K.; Eyzop, D.; Östberg, A.; Janiak, P.; Karlsson, L. Ferrite content measurement in super duplex stainless steel welds. Weld. World 2019, 63, 551-563. [CrossRef]

40. Varbai, B.; Pickle, T.; Májlinger, K. Development and Comparison of Quantitative Phase Analysis for Duplex Stainless Steel Weld. Period. Polytech. Mech. Eng. 2018, 62, 247-253. [CrossRef]

41. Kou, S. Welding Metallurgy, 2nd ed.; John Wiley \& Sons Inc.: Hoboken, NJ, USA, 2003; pp. 68-73.

42. Mizukami, H.; Shirai, Y.; Yamanaka, A.; Watanabe, T. Prediction of Density of Stainless Steel. ISIJ Int. 2000, 40, 987-994. [CrossRef]

43. Mundra, K.; Debroy, T. A general model for partitioning of gases between a metal and its plasma environment. Metall. Mater. Trans. B 1995, 26, 149-157. [CrossRef]

44. Palmer, T.A.; Debroy, T. Physical modeling of nitrogen partition between the weld metal and its plasma environnment. Weld. J. 1996, 75, 197-207.

45. Wada, H.; Pehlke, R.D. Solubility of nitrogen in liquid Fe-Cr-Ni alloys containing manganese and molybdenum. Metall. Trans. B 1977, 8, 675-682. [CrossRef]

46. Kobayashi, Y.; Todoroki, H.; Shiga, N.; Ishii, T. Solubility of Nitrogen in Fe-Cr-Ni-Mo Stainless Steel under a 1 atm N2 Gas Atmosphere. ISIJ Int. 2012, 52, 1601-1606. [CrossRef]

47. Anson, D.R.; Pomfret, R.J.; Hendry, A. Prediction of the Solubility of Nitrogen in Molten Duplex Stainless Steel. ISIJ Int. 1996, 36, 750-758. [CrossRef]

48. Dai, K.; Wang, B.; Xue, F.; Liu, S.; Huang, J.; Zhang, J. Formation of Nitrogen Bubbles During Solidification of Duplex Stainless Steels. Metall. Mater. Trans. B 2018, 49, 2011-2021. [CrossRef]

49. Jiang, Z.; Li, H.; Chen, Z.; Huang, Z.; Zou, D.; Liang, L. The Nitrogen Solubility in Molten Stainless Steel. Steel Res. Int. 2005, 76, 740-745. [CrossRef]

50. Japan Society for the Promotion of Science, the 19th Committee on Steelmaking. Steelmaking Data Sourcebook; Gordon and Breach Science Publishers: New York, NY, USA, 1988.

51. Elliot, J.F.; Gleiser, M. Thermochemistry for Steelmaking; Addison-Wesley Pub. Co: Reading, Mass, UK, 1960. 
52. Hosseini, V.A.; Karlsson, L. Physical and kinetic simulation of nitrogen loss in high temperature heat affected zone of duplex stainless steels. Materialia 2019, 6, 100325. [CrossRef]

53. Varbai, B.; Adonyi, Y.; Baumer, R.; Pickle, T.; Dobránszky, J.; Májlinger, K. Weldability of Duplex Stainless Steels-Thermal Cycle and Nitrogen Effects. Weld. J. 2019, 98, 78-87.

54. Igual Muñoz, A.; García Antón, J.; Guiñón, J.L.; Pérez Herranz, V. Effect of nitrogen in Argon as a shielding gas on tungsten inert gas welds of duplex stainless steels. Corrosion 2005, 61, 693-705. [CrossRef]

55. Hosseini, V.A.; Wessman, S.; Hurtig, K.; Karlsson, L. Nitrogen loss and effects on microstructure in multipass TIG welding of a super duplex stainless steel. Mater. Des. 2016, 98, 88-97. [CrossRef]

(C) 2019 by the authors. Licensee MDPI, Basel, Switzerland. This article is an open access article distributed under the terms and conditions of the Creative Commons Attribution (CC BY) license (http://creativecommons.org/licenses/by/4.0/). 